\title{
Intoxicação espontânea por Crotalaria incana em bovinos no norte do estado do Paraná
}

\section{Spontaneous Crotalaria incana poisoning in cattle in the state of Paraná, Brazil}

\author{
Gustavo Rodrigues Queiroz ${ }^{1}$; Rita de Cássia Lima Ribeiro²; \\ Karina Keller Marques da Costa Flaiban ${ }^{3}$; Ana Paula Frederico Rodrigues \\ Loureiro Bracarense ${ }^{4}$; Júlio Augusto Naylor Lisbôa ${ }^{4 *}$
}

Resumo

As plantas do gênero Crotalaria têm sido descritas como tóxicas para várias espécies de animais domésticos. O objetivo desse trabalho é relatar, pela primeira vez no Brasil, um surto de intoxicação natural por $C$. incana. O surto aconteceu no município de Nova América da Colina, mesorregião norte pioneiro do estado do Paraná, causando a morte de 30 animais de um lote de 223 novilhas para engorda, entre três e cinco anos de idade, que estavam em um piquete invadido por $C$. incana. Os bovinos apresentaram encefalopatia hepática caracterizada por cegueira, depressão e agressividade, evoluindo para a morte em 48 horas. A atividade sérica das enzimas gamaglutamiltransferase e fosfatase alcalina estava aumentada. Congestão hepática e padrão lobular evidente, vesícula biliar aumentada e edema no mesentério próximo à vesícula biliar representaram os principais achados de necropsia. Ao exame histológico observaram-se necrose hepática hemorrágica na região centrolobular com megalocitose e áreas de degeneração esponjosa no tálamo. Os índices de morbidade e de letalidade foram $13,45 \% \mathrm{e}$ $100 \%$, respectivamente. As evidências epidemiológicas, clínicas e patológicas sugerem o diagnóstico de intoxicação por C. incana.

Palavras-chave: Alcalóides pirrolizidínicos, encefalopatia hepática, plantas tóxicas

\begin{abstract}
Plants of genus Crotalaria have been reported as poisonous for many species of domestic animals. The aim of this work is to report, for the first time in Brazil, an outbreak of $C$. incana poisoning. The outbreak took place in Nova América da Colina County, Northern region of Paraná state, Brazil, causing death of 30 Nelore heifers in a herd of 223 animals, between 3 and 5 years old. The animals were grazing on pasture fully infested with $C$. incana. The main clinical signs were characteristic of hepatic encephalopathy and consisted of blindness, depression, aggressiveness, recumbency and death in 48 hours. Gama-glutamyltransferase, and alkaline phosphatase activities were increased. The main necropsy findings were liver congestion and evident lobular pattern, increased gall bladder volume and mesentery oedema near gall bladder. Histological exams showed hepatic hemorrhagic centrolobular necrosis, megalocitosis and spongiform degeneration in thalamus. Morbidity and lethality rates were, respectively, $13,45 \%$ and $100 \%$. Epidemiological, clinical and pathological findings suggest that $C$. incana poisoning was the cause of illness.
\end{abstract}

Key words: Pyrrolizidine alkaloid, hepatic encephalopathy, plant poisoning

1 Médico Veterinário Autônomo. E-mail: gustavorodriguesqueiroz11@gmail.com

2 Prof ${ }^{a}$ Assistente, Hospital Veterinário, Universidade Paranaense, Umuarama, PR. E-mail: ibeiromv@hotmail.com

3 Prof $^{a}$ Adjunta do Dept ${ }^{\mathrm{o}}$ de Medicina Veterinária Preventiva, Centro de Ciências Agrárias, Universidade Estadual de Londrina, UEL, Londrina, PR. E-mail: kkflaiban@uel.br

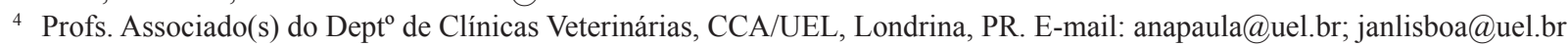

* Autor para correspondência 


\section{Introdução}

Existem mais de 600 espécies de Crotalaria em diversas regiões do mundo e muitas delas são tóxicas para os animais (WILLIAMS; MOLYNEUX, 1987). A toxicidade das espécies de Crotalaria deve-se à presença de alcalóides pirrolizidínicos (NOBRE et al., 2005). No Brasil são descritas intoxicações naturais (NOBRE et al., 2004, 2005; RIET-CORREA et al., 2011) e experimentais (NOBRE et al., 2005; ANJOS et. al., 2010) por C. retusa em ovinos, assim como intoxicações naturais por $C$. retusa em bovinos (NOBRE et al., 2004). Nos bovinos estão também descritas as intoxicações naturais (LEMOS et al., 1997) e experimentais (TOKARNIA; DÖBEREINER, 1982; BOGHOSSIAN et al., 2007) por C. mucronata e experimental por C. anagyroides (TOKARNIA; DÖBEREINER, 1983).

Os casos de intoxicação podem ocorrer pela ingestão natural da planta quando há escassez de alimentos e grande oferta de Crotalaria spp. como invasora das pastagens (LEMOS et al., 1997; RIETCORREA et al., 2011; NOBRE et al., 2005) ou pela contaminação da forragem administrada no cocho com sementes de Crotalaria spp. (LEMOS et al., 1997). As intoxicações em bovinos e ovinos normalmente ocorrem na forma de surtos (LEMOS et al., 1997; NOBRE et al., 2004; RIET-CORREA et al., 2011) e, mais raramente, como casos isolados afetando um ou dois animais do rebanho (NOBRE et al., 2004).

Os sinais clínicos nas intoxicações naturais por C. mucronata em bovinos consistem em emagrecimento progressivo e dispnéia, evoluindo para a morte entre 15 e 30 dias (LEMOS et al., 1997). Os sinais clínicos relatados em bovinos intoxicados naturalmente por C. retusa foram fotossensibilização com duração de 30 a 90 dias, incoordenação, cegueira, edema submandibular, decúbito e morte 48 horas após o início dos sinais de encefalopatia (NOBRE et al., 2004). Nos casos de intoxicação experimental em bovinos por $C$. mucronata os principais sinais observados foram inapetência, taquicardia, taquipnéia, hipomotilidade ruminal e alguns animais apresentaram sinais de distúrbio neurológico (BOGHOSSIAN et al., 2007). Na intoxicação induzida por $C$. anagyroides observaram-se anorexia e emagrecimento progressivo, excitação ou depressão com duração de 9 a 35 dias de evolução até a morte (TOKARNIA; DÖBEREINER, 1983).

As principais lesões histológicas encontradas nas intoxicações por Crotalaria spp. são necrose hepática centrolobular, fibrose hepática e megalocitose podendo se apresentar como um processo de insuficiência hepática aguda (BOGHOSSIAN et al., 2007) ou se caracterizar como um processo de hepatopatia crônica (TOKARNIA; DÖBEREINER, 1983; LEMOS et al., 1997; NOBRE et al., 2004). No caso da C. mucronata observou-se, adicionalmente, espessamento difuso das paredes alveolares e das pequenas arteríolas pulmonares (LEMOS et al., 1997; BOGHOSSIAN et al., 2007), assim como fibrose periarteriolar (BOGHOSSIAN et al., 2007).

A C. incana é uma planta anual, subarbustiva ou herbácea, ereta, ramificada, com caules alvopubescentes, medindo entre 50 e $120 \mathrm{~cm}$ de altura, com reprodução por sementes. Possui folhas alternadas, compostas trifolioladas, com pecíolo pubescente. Os folíolos são obovados com ápice mucronado, glabros na face ventral e pubescentes na dorsal. A sua inflorescência é axilar em racemos de flores amarelo-claras, medindo 10 a $20 \mathrm{~cm}$ de comprimento. Seu fruto é uma vagem oblonga, inflada, tomentoso-pubescente de 35 a $40 \mathrm{~mm}$ de comprimento (LORENZI, 1991).

Há poucas informações na literatura brasileira sobre intoxicações naturais por Crotalaria spp. em bovinos. Não existem relatos na literatura de intoxicações por $C$. incana em bovinos ou em outras espécies de animais domésticos. Há apenas uma sugestão de que essa planta tenha causado surtos de intoxicações em bovinos em Cuba (MARRERO et al., 2004). O objetivo deste relato é descrever os aspectos epidemiológicos, clínicos e patológicos de um surto de intoxicação aguda em bovinos por $C$. incana, no estado do Paraná, sul do Brasil. 


\section{Relato de Caso}

O surto de intoxicação aconteceu no início do mês de junho de 2010, em uma propriedade rural localizada no município de Nova América da Colina, mesorregião norte pioneiro do estado do Paraná. O surto aconteceu em um lote de 223 novilhas Nelore para engorda, com idade entre três e cinco anos. Esses bovinos eram mantidos, há cerca de dois anos, em um pasto nativo de 32 alqueires de Paspalum notatum (grama Mato Grosso) que nunca havia sido reformado ou adubado. Na ocasião da visita à propriedade foi observada invasão intensa por $C$. incana e vestígios de terem sido ingeridas pelos animais. A pouca disponibilidade de forragem consequente à alta lotação (6,9 UA/alqueire) e à baixa precipitação pluviométrica foi o fator que contribuiu para que os animais consumissem grande quantidade da planta invasora. No período de um mês morreram 30 novilhas com histórico de manifestações e evolução clínicas semelhantes: aparecimento súbito de andar sem rumo, andar cambaleante, colidir contra obstáculos, cegueira, agressividade ou depressão e evolução para o decúbito e morte em 24 a 48 horas.

Durante as visitas à propriedade foram realizados exame físico, colheita de sangue e de líquor, eutanásia e necropsia das últimas duas novilhas que adoeceram no surto. Foram colhidos vários exemplares da planta para identificação botânica da espécie, que foi classificada como Crotalaria incana (Figura 1). Um exemplar foi depositado no Herbário da Universidade Estadual de Londrina com o registro de FUEL 323702. A inspeção do lote de novilhas no qual se observaram as mortes revelou que a maioria dos animais apresentava escore de condição corporal baixo (entre 1 e 2 na escala de 1 a 5$)$.

Figura 1. Aspectos morfológicos da Crotalaria incana observada no município de Nova América da Colina, PR, com destaque para as inflorescência (A) e vagens oblongas e folhas trifolioladas com folíolos obovados (B).

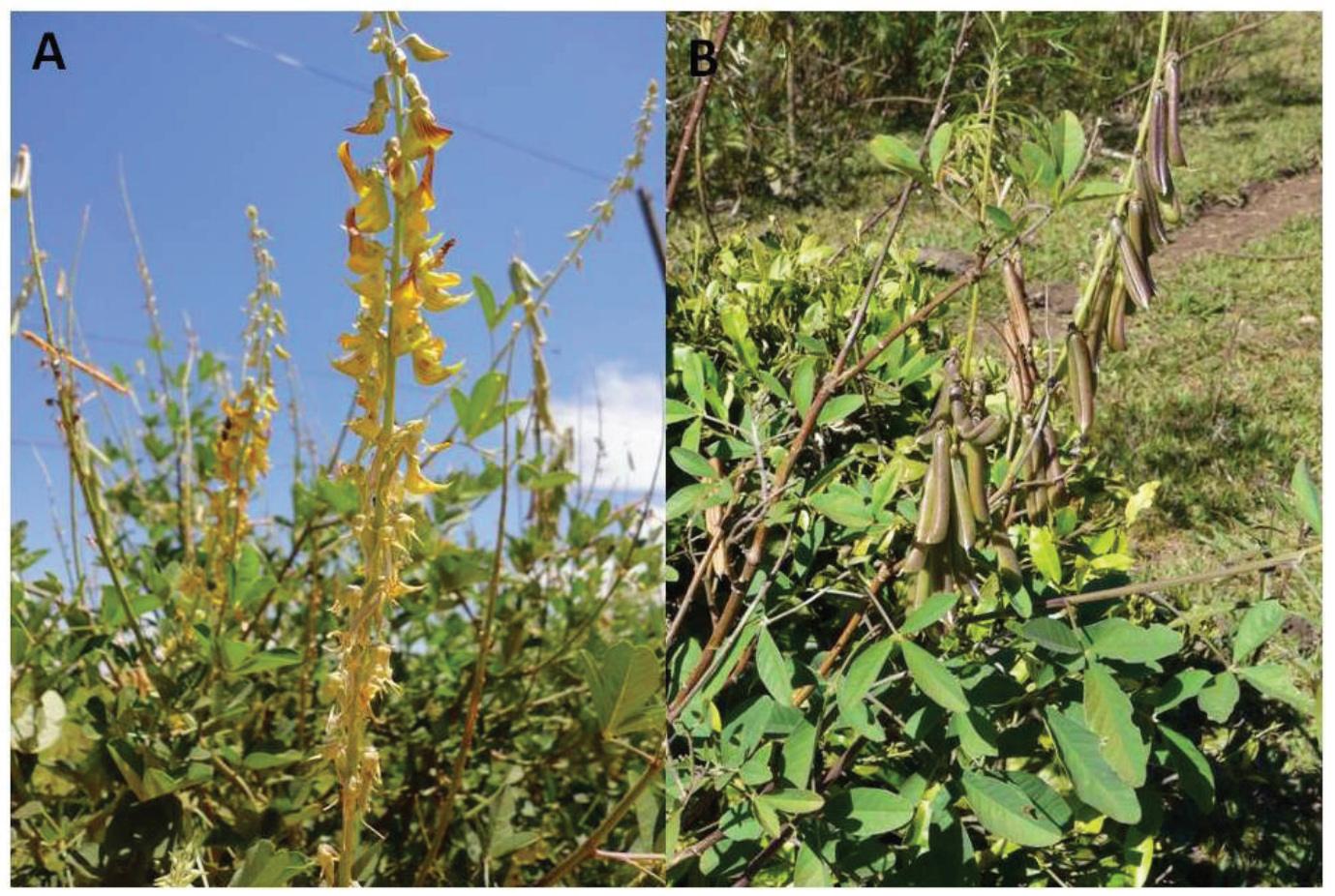

Fonte: Elaboração dos autores. 
O bovino 1 era uma fêmea Nelore de 4 anos de idade. Os funcionários relataram que no período da manhã a novilha era capaz de se manter em estação, estava aparentemente cega, deprimida e caminhava sem rumo. No período da tarde foi examinada em decúbito esternal permanente e apresentava frequência cardíaca $(68 \mathrm{bpm})$ e respiratória (20 $\mathrm{mpm}$ ) dentro dos intervalos fisiológicos, hipotermia $\left(34,8^{\circ} \mathrm{C}\right)$, atonia ruminal, mucosas congestas, tremores musculares na região do pescoço e na face, trismo mandibular e depressão intensa, mantendo acuidade visual aparentemente normal. Essa novilha estava magra (escore de condição corporal 1) e possuía pelagem irregular e pêlos secos e sem brilho.

O bovino 2 também era uma fêmea Nelore, com 4 anos de idade e com condição corporal melhor do que a primeira novilha (escore de condição corporal 2). Na véspera de ser examinada apresentou quadro súbito caracterizado por afastamento do rebanho, inapetência, andar cambaleante, colisão contra obstáculos e agressividade. Ao exame físico apresentou frequência cardíaca (64 bpm) e respiratória $(28 \mathrm{mpm})$ dentro dos valores fisiológicos, hipotermia $\left(34,7^{\circ} \mathrm{C}\right)$, hipomotilidade ruminal (3 movimentos incompletos em 5 min), incoordenação com paresia dos membros posteriores, agressividade, tremores musculares no pescoço, cegueira do olho direito, diminuição da acuidade visual do lado esquerdo e apoiava a cabeça contra obstáculos.

Amostras de sangue foram colhidas por meio da punção da veia jugular com uso de frascos a vácuo sem anticoagulante e frascos contendo EDTA. As colheitas de líquor foram realizadas pela punção no espaço atlantooccipital, utilizando a agulha metálica do cateter intravenoso (BD Angiocath ${ }^{\mathrm{TM}}$ ) $18 \mathrm{G}$ com $5 \mathrm{~cm}$ de comprimento. Todo o material foi mantido refrigerado $\left(2^{\circ} \mathrm{C}\right.$ a $\left.8^{\circ} \mathrm{C}\right)$ até a chegada ao laboratório. $\mathrm{O}$ protocolo de eutanásia foi realizado por via intravenosa e consistiu em sedação com xilazina $2 \%$ (Copazine, Coopers ${ }^{\circledR}$ ), na dose de $0,2 \mathrm{mg} / \mathrm{kg}$, em anestesia geral com tiopental
(Thiopentax, Cristália ${ }^{\circledR}$ ), na dose de $10 \mathrm{mg} / \mathrm{kg}$, e na indução da parada cardíaca com $300 \mathrm{~mL}$ da solução de $\mathrm{KCl} 20 \%$. O exame necroscópico foi realizado nas duas novilhas estudadas, logo após a sua morte. Fragmentos de baço, linfonodos, fígado, abomaso, músculos esqueléticos, miocárdio, pulmão, rim, intestino e sistema nervoso central, incluindo gânglio do nervo trigêmeo, rete mirabile carotídea e a hipófise, foram colhidos.

O hemograma foi realizado em aparelho hematológico modelo MS4 (Melet Schloesing Laboratoires $^{\circledR}$ ) e a contagem diferencial dos leucócitos foi realizada em esfregaços sanguíneos frescos corados pela técnica de Romanowsky (Panótico Rápido ${ }^{\circledR}$ LB; Laborclin). A determinação da concentração de proteína plasmática total foi realizada por refratometria e a concentração do fibrinogênio plasmático foi determinada pelo método da precipitação pelo calor, seguida de leitura por refratometria. No soro sanguíneo foram realizadas as mensurações das atividades das enzimas gamaglutamiltransferase (GGT), aspartato aminotrasferase (AST), creatina quinase (CK) e fostatase alcalina (FA), e das concentrações de ureia e de creatinina por técnicas cinéticas colorimétricas a $37^{\circ} \mathrm{C}$, e leitura espectrofotométrica. As mensurações da proteína total (PT), albumina e bilirrubinas total (BT) e direta (BD) foram realizadas por métodos colorimétricos com leitura espectrofotométrica. O aparelho de bioquímica úmida modelo BS120 (Mindray Chemistry Analyzer ${ }^{\circledR}$ ) e os reagentes comerciais específicos $\left(\right.$ Dialab $\left.^{\circledR}\right)$ foram empregados nessas determinações. A bilirrubina indireta (BI) foi calculada por subtração entre BT e BD.

No líquor foram avaliadas as características físico-químicas e as contagens global e diferencial de células nucleadas e de hemácias. A contagem global foi realizada em câmara de Fuchs-Rosenthal e a contagem diferencial em esfregaço corado com pela técnica de Romanowsky (Panótico Rápido LB; Laborclin $\left.^{\circledR}\right)$. As determinações da concentração de proteína e de glicose foram realizadas pela técnica colorimétrica $\left(\right.$ Dialab $\left.^{\circledR}\right)$ com leitura 
espectrofotométrica (BS120; Mindray Chemistry Analyzer $\left.{ }^{\circledR}\right)$.

Os fragmentos de tecido colhidos durante a necropsia foram fixados em formol a $10 \%$, processados rotineiramente para estudo histológico e corados pela coloração de hematoxilina e eosina (HE).

Não foram detectadas alterações no líquor de ambas as novilhas examinadas e as alterações hematológicas limitaram-se à inversão da relação neutrófilo:linfócito devida ao aumento do número de neutrófilos segmentados circulantes, caracterizando o leucograma de estresse. O bovino 2 apresentou elevação discreta do volume globular $(45,2 \%)$ e da concentração da PPT $(8,4 \mathrm{~g} / \mathrm{dL})$ caracterizando hemoconcentração decorrente, provavelmente, da desidratação. A concentração do fibrinogênio estava dentro dos valores de referência para a espécie (400 $\mathrm{mg} / \mathrm{dL}$ em ambos).

As alterações bioquímicas foram consistentes em ambos os bovinos e caracterizaram-se por elevação acentuada nas atividades da GGT (70,6 $\mathrm{UI} / \mathrm{L}$ e $105,4 \mathrm{UI} / \mathrm{L})$ e da FA (732 UI/L e $612 \mathrm{UI} / \mathrm{L})$ e elevação discreta na atividade da CK (573,3 UI/L e 473,3 UI/L) e nas concentrações de ureia (43 mg/ $\mathrm{dL}$ e $55 \mathrm{mg} / \mathrm{dL})$ e da PT (9,2 g/dL e 10,8 g/dL). As concentrações das bilirrubinas estavam aumentadas somente no bovino 2 (BT: 1,5 mg/dL; BD: 0,7 mg/ dL; e BI: 0,8 mg/dL). Apesar das elevações da GGT e da FA, a atividade da AST, curiosamente, não se apresentava elevada em nenhum dos dois bovinos (46,6 UI/L e 37,0 UI/L).
Os achados de necropsia foram semelhantes nas duas novilhas examinadas. As principais lesões macroscópicas foram congestão hepática acentuada com padrão lobular evidente ao corte, vesícula biliar repleta, edema em mesentério próximo à vesícula biliar, rins com áreas pálidas na cortical, mucosa do duodeno espessada discretamente, petéquias na serosa do rúmen e do retículo e no tecido subcutâneo da região do tórax. Somente no bovino 2 o coração apresentava consistência flácida com petéquias no miocárdio. O fígado exibia coloração vermelho escura homogênea sob a cápsula e, apesar da congestão, a hepatomegalia era discreta (Figura 2). Nos outros órgãos nenhuma alteração significativa foi observada.

A necrose hemorrágica centrolobular foi a principal lesão encontrada nos dois bovinos (Figura 2). Megalocitose dos hepatócitos foi observada nas áreas onde não havia necrose (Figura 2). O bovino 2 também apresentou focos de fibrose hepática na região centrolobular. Nos rins do bovino 1 observouse congestão medular e tumefação das células do epitélio tubular. No sistema nervoso central do bovino 1 foram encontrados edema (Figura 2) e espongiose no tálamo e na substância branca do cerebelo e hemorragia perivascular no colículo rostral. No outro bovino foram observados edema perivascular e perineuronal na substância cinzenta do córtex frontal e do córtex parietal e edema perivascular focal na ponte. Não foram observadas lesões pulmonares em nenhum dos dois bovinos. 
Figura 2. Lesões histológicas observadas em bovinos naturalmente intoxicados por Crotalaria incana: necrose hemorrágica centrolobular; HE, bar $100 \mu \mathrm{m}$, (A); megalocitose; HE, bar $30 \mu \mathrm{m}$, (B); congestão hepática (C); edema perineuronal e perivascular no tálamo; HE, bar $50 \mu \mathrm{m}$, (D).

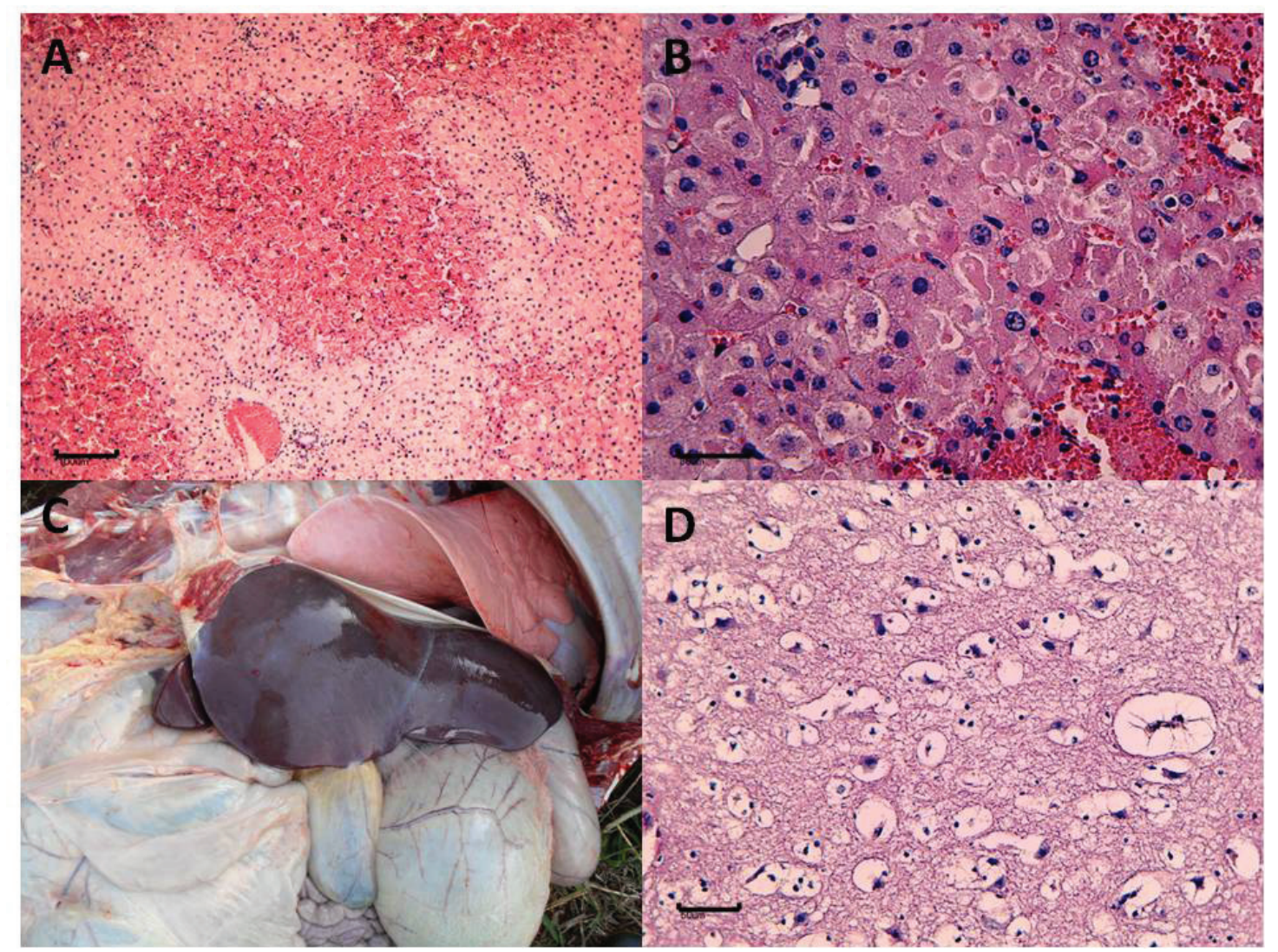

Fonte: Elaboração dos autores.

\section{Discussão e Conclusão}

O diagnóstico de intoxicação por $C$. incana foi baseado nos dados epidemiológicos, nos sinais clínicos, na bioquímica sérica e nos achados histopatológicos, tratando-se do primeiro relato de intoxicação por essa espécie de crotalária em animais. Embora em bovinos normalmente ocorram intoxicações crônicas por alcalóides pirrolizidínicos, nesse surto as alterações histológicas encontradas são características de disfunção aguda. Alterações como necrose hemorrágica centrolobular aguda, associadas a sinais clínicos nervosos, alterações significativas na função hepática e lesões microscópicas no sistema nervoso central compatíveis com encefalopatia hepática estão em consonância com os relatos de intoxicações por $C$. retusa em ovinos (NOBRE et al., 2005; ANJOS et al., 2010; RIET-CORREA et al., 2011).

Os índices de morbidade e letalidade desse surto foram, respectivamente, $13,45 \%$ e $100 \%$. Lemos et al. (1997) relataram índices de morbidade $(1,07 \%)$ e mortalidade $(0,92 \%)$ muito mais baixos em surto de intoxicação por C. mucronata em bovinos no estado de Minas Gerais. Porém, a taxa de letalidade $(85,7 \%)$ também foi muito elevada, ainda que não absoluta. Índices altos foram igualmente observados em um surto de intoxicação aguda por C. retusa em ovinos na Paraíba (22,7\% de morbidade e $100 \%$ de letalidade) (RIET-CORREA et al., 2011). Essas observações indicam que a intoxicação é quase sempre fatal e que a morbidade pode variar em cada situação de acordo com os fatores de risco 
envolvidos e a gravidade dos mesmos. O manejo extensivo, a escassez de forragem e a abundância de exemplares de Crotalaria invadindo a pastagem podem ser apontados como fatores de semelhança entre os três surtos.

Ao contrário do quadro agudo observado nas novilhas intoxicadas por $C$. incana, o curso clínico das intoxicações naturais de bovinos por $C$. mucronata variou de 15 a 30 dias e observaram-se emagrecimento progressivo e dispnéia (LEMOS et al., 1997). Nobre et al. (2004) relataram três casos de intoxicação por $C$. retusa em bovinos. Dois animais com quadro crônico exibiram fotossensibilização por 30 a 90 dias, e morreram 48 horas após o aparecimento dos outros sinais clínicos. Assemelhando-se às novilhas do presente relato, o outro bovino apresentou quadro agudo de encefalopatia e morte em 48 horas. Nos surtos de intoxicação em ovinos por $C$. retusa o curso clínico também foi agudo, com manifestação de depressão, incoordenação e decúbito permanente, evoluindo para a morte em 2 a 5 dias (NOBRE et al., 2005; RIET-CORREA et al., 2011).

Nas intoxicações experimentais a variabilidade das manifestações também foi considerável. Tokarnia e Döbereiner (1982) intoxicaram bovinos com C. mucronata e observaram sinais clínicos somente nos animais que receberam doses únicas de $25 \mathrm{~g} / \mathrm{kg}, 60 \mathrm{~g} / \mathrm{kg}$ e $80 \mathrm{~g} / \mathrm{kg}$ das folhas frescas, com evolução para a morte entre 16 e 68 horas após a ingestão. Tremores musculares generalizados, fezes secas com estrias de sangue, anorexia, focinho seco, extremidades frias, hipotonia ou atonia ruminal, taquicardia e decúbito esternal preferencial estavam presentes. Boghossian et al. (2007) realizaram a intoxicação por C. mucronata utilizando somente as suas sementes moídas. Os animais que receberam doses diárias de 5 a $10 \mathrm{~g} / \mathrm{kg}$ desenvolveram doença após 47 a 60 dias de ingestão e morreram entre 3 horas e 5 dias após o início dos sinais. Inapetência, taquicardia, taquipneia com respiração abdominal, hipotonia ruminal e pulso venoso positivo foram os principais sinais apresentados. Sinais de distúrbio neurológico como nistagmo, midríase, hiperexcitação e opistótono foram notados em dois bovinos.

A elevação da GGT também foi relatada em uma vaca intoxicada naturalmente por C. retusa (NOBRE et al., 2004). Ao contrário das evidências do presente relato, a atividade da AST mantevese elevada e a atividade da FA não se alterou em bezerros intoxicados experimentalmente por $C$. saltiana (BARRI; ADAM, 1981). Nos casos experimentais ou naturais envolvendo ovinos e a C. retusa, as atividades da AST e da GGT também se comprovaram sempre elevadas e a atividade da FA não foi mensurada (NOBRE et al., 2005; ANJOS et al., 2010; RIET-CORREA et al., 2011). $\mathrm{Na}$ única oportunidade em que foi mensurada, a BD se apresentou igualmente elevada (RIET-CORREA et al., 2011). O conjunto dos resultados indica claramente o potencial hepatotóxico das crotalárias.

Nobre et al. (2004) relataram que, em casos de intoxicação por C. retusa em bovinos, os fígados estavam endurecidos e com padrão lobular evidente, caracterizando, ao contrário do presente relato, processo crônico de hepatopatia. O mesmo foi observado nos bovinos intoxicados experimentalmente por $C$. anagyroides (TOKARNIA; DÖBEREINER, 1983). Nas intoxicações experimentais em bovinos por $C$. mucronata as lesões consistiram unicamente em hidrotórax e edema pulmonar acentuado (TOKARNIA; DÖBEREINER, 1982). A alteração hepática macroscópica também não foi consistente em estudo mais recente, no qual alguns bezerros exibiram alterações discretas a moderadas na coloração do fígado e apenas um animal apresentou evidenciação moderada do padrão lobular (BOGHOSSIAN et al., 2007).

Em surtos de intoxicações em ovinos por $C$. retusa as lesões caracterizaram-se por fígado com aparência de noz moscada (NOBRE et al., 2005) ou difusamente avermelhado com evidenciação do padrão lobular e áreas irregulares de coloração 
vermelho escuro alternando com áreas pálidas (RIET-CORREA et al., 2011). A icterícia, o hidrotórax e o hidroperitônio estavam presentes nos ovinos (NOBRE et al., 2005; RIET-CORREA et al., 2011). As últimas alterações não foram observadas nas novilhas necropsiadas.

Lemos et al. (1997) realizaram três necropsias em um surto de intoxicação por C. mucronata em bovinos e a lesão hepática caracterizada por consistência firme e áreas acinzentadas foi observada em um único animal. A pneumonia intersticial foi o principal problema observado nesses animais (LEMOS et al., 1997). As novilhas examinadas no presente relato não exibiam qualquer alteração no sistema respiratório.

A principal lesão histopatológica presente nos bovinos intoxicados por $C$. incana também esteve presenteemalguns bovinos intoxicados naturalmente (LEMOS et al., 1997) ou experimentalmente por C. mucronata (BOGHOSSIAN et al., 2007), e nos ovinos intoxicados por $C$. retusa (NOBRE et al., 2005; ANJOS et al., 2010; RIET-CORREA et al., 2011) o que confirma o potencial da planta em provocar a insuficiência hepática aguda. Nos bovinos intoxicados naturalmente por C. retusa, observou-se lesão semelhante somente naquele que exibiu o quadro de evolução aguda (NOBRE et al., 2004), como as novilhas investigadas no presente relato. Contrariando as demais evidências, Tokarnia e Döbereiner (1982) não encontraram alterações histológicas consistentes nos bovinos intoxicados experimentalmente por C. mucronata. Entretanto, na intoxicação experimental por $C$. anagyroides a cirrose hepática foi a lesão padrão (TOKARNIA; DÖBEREINER, 1983).

A C. incana não provocou lesão pulmonar, diferentemente da C. mucronata. No caso da última planta a lesão hepática nem sempre estava presente e as principais lesões histológicas localizavam-se nos pulmões e caracterizavam-se por espessamento da parede alveolar, pela fibrose intersticial com infiltrado mononuclear e de eosinófilos e pelo espessamento da parede das pequenas arteríolas (LEMOS et al., 1997; BOGHOSSIAN et al., 2007).

Os alcalóides pirrolizidínicos são os princípios tóxicos das plantas do gênero Crotalaria. $\mathrm{Na} C$. retusa denomina-se monocrotalina (NOBRE et al., 2005; ANJOS et al., 2010) e na $C$. incana é a anacrotina (MATTOCKS; DRIVER, 1987). Esses alcalóides são essencialmente hepatotóxicos, mas alguns exercem efeito nos pulmões, como a monocrotalina (SANTOS et al., 2008). Conforme esclareceram os últimos autores em seu artigo de revisão, parte dos alcalóides ingeridos é excretada de forma inalterada; outra parte é metabolizada no fígado por meio de reações de desidrogenação, originando os pirróis tóxicos. Estes lesionam as células hepáticas por inibição da mitose, causando megalocitose, necrose e redução do número de hepatócitos, que são substituídos por tecido fibroso mais tarde. Parte dos pirróis tóxicos produzidos no fígado escapa para a circulação e atinge outros tecidos como rins e pulmões. Nos pulmões, assim como ocorre no fígado, também há produção de pirróis, pois aquele tecido também possui as enzimas do sistema citocromo $\mathrm{P} 450$, responsáveis pela metabolização dos alcalóides pirrolizidínicos.

Lesões hepáticas difusas agudas ou crônicas podem ser acompanhadas pela manifestação de encefalopatia hepática (LUCENA et al., 2010), como observado no surto relatado. Segundo estes autores, a encefalopatia hepática em bovinos tem início abrupto e caracteriza-se, mais frequentemente, como a manifestação terminal da doença hepática crônica. Entretanto, no presente relato, os animais apresentaram doença hepática aguda. As lesões histológicas presentes no encéfalo são compatíveis com o processo de encefalopatia hepática e se assemelham às observações de Anjos et al. (2010) em ovinos intoxicados por C. retusa.

O diagnóstico diferencial deve ser estabelecido para todas as plantas hepatotóxicas e para as plantas que causam lesão primária no sistema nervoso central. Em função dos sinais de distúrbio 
neurológico devido à encefalopatia hepática, devese também estabelecer o diagnóstico diferencial para a raiva e para outras doenças agudas que acometem o encéfalo, provocando especificamente a síndrome cerebral.

As observações no surto investigado indicam que bovinos famintos devido à falta de pastagem podem se intoxicar por $C$. incana experimentando insuficiência hepática aguda e manifestando encefalopatia hepática rapidamente fatal. No presente relato as novilhas exibiram exclusivamente o quadro agudo, sugerindo que essa seja a forma de apresentação esperada para a intoxicação por C. incana. As discrepâncias entre as observações dos diferentes autores quanto às manifestações presentes, o tempo de evolução para a morte e a característica do quadro, agudo ou crônico, podem ser devidas à espécie de Crotalaria causadora da doença, à quantidade e parte da planta ingerida e à espécie que a ingere. Estudos adicionais poderão confirmar se a doença aguda é, de fato, a forma de apresentação padrão na intoxicação por $C$. incana em bovinos.

\section{Agradecimentos}

À Professora Ana Odete Santos Vieira do Departamento de Biologia Animal e Vegetal da Universidade Estadual de Londrina pela classificação botânica da planta. Ao Ministério da Agricultura, Pecuária e Abastecimento/Conselho Nacional de Desenvolvimento Científico e Tecnológico pelo apoio financeiro (MAPA/CNPq processo $n^{\circ} 578645 / 2008-4$ ).

\section{Referências}

ANJOS, B. L.; NOBRE, V. M. T.; DANTAS, A. F. M.; MEDEIROS, R. M. T.; OLIVEIRA NETO, T. S.; MOLYNEUX, R. J.; RIET-CORREA, F. Poisoning of sheep by seeds of Crotalaria retusa: Acquired resistance by continuous administration of low doses. Toxicon, v. 55 , n. 1, p. 28-32, 2010.
BARRI, M. E. S.; ADAM, S. E. I. The toxicity of Crotalaria saltiana to calves. Journal of Comparative Pathology, v. 91, n. 4, p. 621-627, 1981.

BOGHOSSIAN, M. R.; PEIXOTO, P. V.; BRITO, M. F.; TOKARNIA, C. H. Aspectos clínico-patológicos da intoxicação experimental pelas sementes de Crotalaria mucronata (Fabaceae) em bovinos. Pesquisa Veterinária Brasileira, Seropédica, v. 27, n. 4, p. 149-156, 2007.

LEMOS, R. A. A.; DUTRA, I. S.; SOUZA, G. F.; NAKAZATO, L.; BARROS, C. S. L. Intoxicação espontânea por Crotalaria mucronata em bovinos em Minas Gerais. Arquivos do Instituto Biológico, São Paulo, v. 64, p. 43, 1997. Suplemento.

LORENZI, H. Plantas daninhas do Brasil: terrestres, aquáticas, parasitas, tóxicas e medicinais. 2. ed. Nova Odessa: Plantarum, 1991. 270 p.

LUCENA, R. B.; RISSI, D. R.; MAIA, L. A.; FLORES, M. M.; DANTAS, A. F. M.; NOBRE, V. M. T.; RIETCORREA, F.; BARROS, C. S. L. Intoxicação por alcalóides pirrolizidínicos em ruminantes e equinos no Brasil. Pesquisa Veterinária Brasileira, Seropédica, v. 30, n. 5, p. 447-452, 2010.

MARRERO, E.; APARICIO, M.; FIGUEREDO, M. A.; BULNES, C.; SÁNCHEZ, L. M.; PALENZUELA, I.; DURAND, R. Common natural and experimental plant intoxications in animals reported in Cuba. p. 335-340. In: ACAMOVIC, T.; STEWART, C. S.; PENNYCOTT, T. W. Poisonous plants and related toxins. Wallingford, UK: CABI Publ., 2004.

MATTOCKS, A. R.; DRIVER, H. E. Metabolism and toxicity of anacrotine, a pyrrolizidine alkaloid, in rats. Chemical Biological Interactions, v. 63, n. 1, p. 91-104, 1987.

NOBRE, V. M. T.; DANTAS, A. F. M.; RIET-CORREA, F.; BARBOSA FILHO, J. M.; TABOSA, I. M.; VASCONSELOS, J.S. Acute intoxication by Crotalaria retusa in sheep. Toxicon, v. 45, n. 3, p. 347-352, 2005.

NOBRE, V. M. T.; RIET-CORREA, F.; DANTAS, A. F. M.; TABOSA, I. M.; MEDEIROS, R. M. T.; BARBOSA FILHO, J. M. Intoxication by Crotalaria retusa in ruminants and equidae in the state of Paraíba, northweastern, Brazil. In: ACAMOVIC, T.; STEWART, C. S.; PENNYCOTT, T. W. Poisonous plants and related toxins. Wallingford, UK, CABI Publ., 2004. p. 275-279.

RIET-CORREA, F.; CARVALHO, K. S.; DANTAS, A. F. M.; MEDEIROS, R. M. T. Spontaneous acute poisoning by Crotalaria retusa in sheep and biological control of this plant with sheep. Toxicon, v. 58, n. 6-7, p. 606-609, 2011. 
SANTOS, J. C. A.; RIET-CORREA, F.; SIMÕES, S. V. D.; BARROS, C. S. L. Patogênese, sinais clínicos e patologia das doenças causadas por plantas hepatotóxicas em ruminantes e equinos no Brasil. Pesquisa Veterinária Brasileira, Seropédica, v. 28, n. 1, p. 1-14, 2008.

TOKARNIA, C. H.; DÖBEREINER, J. Intoxicação experimental por Crotalaria mucronata (Leg. Papilionoideae) em bovinos. Pesquisa Veterinária Brasileira, Seropédica, v. 2, n. 2, p. 77-85, 1982.
Intoxicação experimental por Crotalaria anagynoides (Leg. Papilionoideae) em bovinos. Pesquisa Veterinária Brasileira, Seropédica, v. 3, n. 4, p. 115-123, 1983.

WILLIAMS, M. C.; MOLYNEUX, R. J. Occurrence, concentration, and toxicity of pyrrolizidine alkaloids in Crotalaria seeds. Weed Science, Champaign, v. 35, n. 4, p. 476-481, 1987. 